\title{
Optimizing the sterilization process of canned food using temperature distribution studies
}

\author{
Ibrahim. M. Ismail ${ }^{1}$, Alaa Fahmy ${ }^{1}$, Ahmed Azab ${ }^{1}$, Magdy Abadir ${ }^{1}$, \\ Seif-Eddeen Fateen ${ }^{1}$ \\ ${ }^{1}$ (Department of Chemical Engineering, Faculty of Engineering, Cairo University, Giza, Egypt)
}

\begin{abstract}
The thermal processing of canned food is the most important step in the canning procedure. Retort operating procedures must ensure that uniform processing temperature is achieved and maintained throughout the locations of the canned containers during the process. In this study, temperature distribution tests have been used as a means of verifying the temperature uniformity around the containers. These studies were carried out in two Egyptian canning plants in horizontal water-immersion and water-spray retorts under fully loaded operating conditions. Time-temperature data gathered were used as a guidance tool in improving temperature distribution and in optimizing the process schedule.
\end{abstract}

Keywords : Temperature Distribution, Canning, Optimization, Retorts, Thermal Processing

\section{INTRODUCTION}

The simplest and most effective means of storing a large part of our food supply is by canning, in which preservation by heat or thermal processing is used to provide a safe and palatable product. The thermal processing of canned foods, commonly known as "cooking, retorting, or processing" is the application of heat at a specified temperature for a specified time. This operation has two fundamental purposes. The first is to produce a commercially sterile product. The product is contained in a hermetically sealed container and is subjected to heat treatment at a temperature and for a time sufficient to destroy all organisms that might adversely affect the consumer's health. Heat treatment also destroys more resistant organisms that could produce spoilage under normal storage conditions. The second purpose is to cook the food to a point where a minimum of further preparation is necessary for its consumption. Obviously, the processing equipment for this most important operation must be properly installed, equipped, and operated in accordance with proven practices.

Retorts are closed pressure type vessels that use steam from an outside source such as steam boilers or steam generators. The first retorts using steam from an outside source were invented by A. K. Shriver about 1875 [1]. Non-agitating (still) retorts operating in a pure steam environment are the most simple from both operational and control aspect. These batch retorts can be oriented either vertically or horizontally. They are designed to process only metal cans with double seams. Currently, in addition to metal cans, food can also be packaged in in glass, plastic, semi-ridge, and flexible materials. Retorts that are capable of overpressure are needed to process these materials [2]. Retorts operating with overpressure include steam/air retorts, water shower, water sprays, and water immersion.

No matter what type of a retort system is used in a canning facility, the retort operating procedures must ensure that uniform processing temperature is achieved and maintained throughout the location of containers during the process [3]. Uniform temperatures within the retort must occur by the end of the retort come-up time, which is the period from the time steam is admitted into the retort until the process timing begins.

Regardless of the processing fluid (steam, water, steam/air, water spray), the time at which the retort reaches the operating temperature must be known and it must be possible to verify that the retort stays at the process temperature [4]. To measure the process temperature, a thermometer is mounted in the retort shell. For practical reasons, the thermometer is placed remote from the containers and the heating fluid immediately surrounding the containers being processed. Regulations require the use of a mercury-in-glass thermometer [5].

Temperature distribution tests assist in establishing operating procedures for all retort types. Temperature sensors or thermocouples are located between containers throughout the retort load. The temperatures are monitored during the process to ensure that the temperature indicating device or mercury-inglass thermometer for the retort is representative of the temperatures throughout the inside of the retort [2]. The data from this test provide a profile of the temperature distribution within the retort.

The resistance to flow introduced by crates, racks, or separator sheets will affect temperature distribution. Crates with little open area will be more difficult to vent than crates with large open area. Crates 
that use separator sheets between layers are very common in canning facilities. The more layers per crate the more difficult the task of obtaining good temperature distribution.

Since the understanding of the temperature distribution inside the retort is vital for optimizing the sterilization process, several studies have been published that present the results of both experimental and simulation attempt to identify the temperature distribution profiles inside retorts. Recent published numerical simulation studies included the sterilization of canned liquid food using sucrose degradation as an indicator [6], the use of artificial neural networks for modeling the sterilization process [7] and the prediction of the temperature variation of the slowest heating zone with time [8]. Recent experimental attempts included the use of an experimental design methodology to optimize the processing conditions for the sterilization of retorted short-rib patties [9] and various real-time retort control studies [10-12].

The aim of this study is to optimize the performance of the sterilization process through conducting and analyzing temperature distribution studies. The methodology explained in Section II is applied successfully to two retorts. Results are presented and discussed in Section III. While Section IV summarizes the conclusions of this study.

\subsection{Retort Description}

\section{MATERIALS AND MethodS}

The temperature distribution studies were conducted at two commercial canning facilities in the Cairo metropolitan area. The two facilities had a conventional horizontal retorts. Plant A has a water immersion retort and Plant B has a water spray retort. A general retort description is shown in Fig. 1.

\subsubsection{Retort A (Water Immersion)}

The retort is a horizontal type that use water as the heating medium. Water is heated by direct steam injection which condenses and lose its latent heat as it heats up the water that initially fills the retort. The retort is about $19.7-\mathrm{ft}(6-\mathrm{m})$ long and $4.9-\mathrm{ft}(1.5-\mathrm{m})$ in diameter. It holds 6 baskets of product. Each basket, has a rectangular shape of $1 \mathrm{~m}$ in width, $0.8 \mathrm{~m}$ in length and $0.8 \mathrm{~m}$ in height. Each of the open holes at the bottom of the basket is $3 / 4$ inch $(1.9 \mathrm{~cm})$ in diameter with center-to-center spacing of $1.5 \mathrm{inch}$. Thus the open area constitutes about $30 \%$ of the area of the basket bottoms.

Divider sheets were used between rows. The hole size was 1 inch on 1.5 inch center to center. The water supply for the retort came from ground well through a 3 -inch inlet pipe. The spreader was a rectangular duct of 8-inch $\times 2$-inch cross sectional area through which the holes pass. The hole diameter was 0.5 inch on 4 inches center to center. The steam supply for the retort came from the boiler of 6 bar in pressure and header pipe size of 2.5 inch through a pipe of 2.5 inch in size from header to supply valve. The air inlet was 2 inch pipe size with a check valve and was located at $1 \mathrm{~m}$ from the door.

The retort had one steam inlet pipe to the retort of 2.5 inch and 2 spreader pipes of 2 inch in diameter, each having 60 holes of $1 / 2$-inch $(12.7 \mathrm{~mm})$ diameter on 2.5 inch center to center. The drain was a 3 -inch pipe and was located at $1 \mathrm{~m}$ from fan. The retort had two venting pipes. The small vent pipe of $1.5 \mathrm{inch}$ was located at $6.6 \mathrm{ft}(2 \mathrm{~m})$ from door and the large vent of 3 inch was located at $5 \mathrm{ft}(1.5 \mathrm{~m})$ from door.
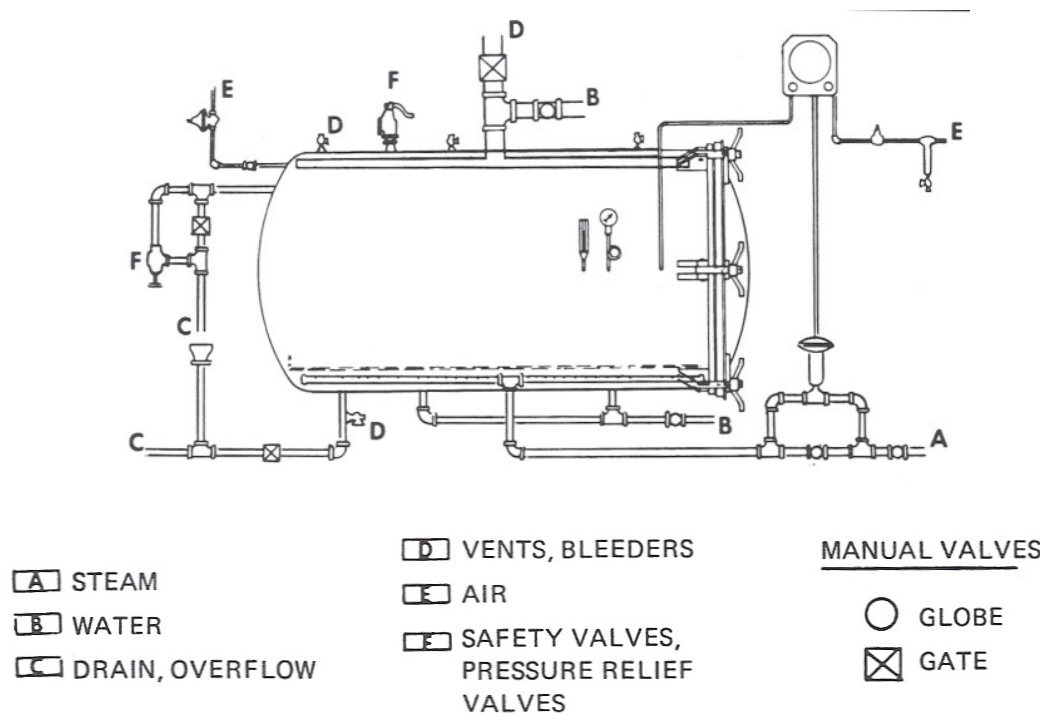

Fig. 1 Schematic drawing of a horizontal report 


\subsubsection{Retort B (Water Spray)}

The retort was about $6-\mathrm{m}$ long and about $1.2-\mathrm{m}$ in diameter. It held 6 baskets of product. Each basket held 6 layers of cans. Divider sheets between the layers of cans were not used. The basket was about $1 \mathrm{~m} \mathrm{x1} \mathrm{m} \mathrm{x}$ $1 \mathrm{~m}$ in size and was made of stainless steel wire.

The holes between the wires were about $5 \mathrm{~cm} \times 5 \mathrm{~cm}$. The retort had no mercury in glass thermometer. The retort is cascading water (spray) type, in which the heating medium was hot water. The water distribution system was located at the top of the retort to allow heating and cooling water to cascade (rain down) over the containers. Air was a source of overpressure. The water was heated externally by a heat exchanger and was pumped through the system.

\subsection{Measurement Tools}

\subsubsection{Standard Thermocouple}

A copper-constantan of the order of 5 millivolts or less for a temperature difference between the junctions of $180^{\circ} \mathrm{F}\left(100^{\circ} \mathrm{C}\right)$ or less was used. It was manufactured locally by Al-Allammia Co. for measuring instruments.

\subsubsection{Extension Wires Connector}

Stressed and well-insulated extension wires of the same type were used. Wires were joined by the use of plug-in thermocouples male connectors. The connection points were crimped after insertion of the wires. The extension wires were connected to the potentiometer using jack-type connections. Care was taken to see that the wires were clean at the connection points.

\subsubsection{Data Logger}

As several thermocouples were to be read, they were connected to a multi-channel switch which was in turn connected to a potentiometer. Data logging systems had a multi-channel temperature measurement combined with digital data output; this instrument was manufactured to mate with specific thermocouple types. A digital data output made data gathering easier and opened up the possibility of direct analyses of heat penetration data by a computer. This system also enabled numerous measurements of many different temperatures within the span of a minute enhancing computer data analysis. The data logger was properly grounded to prevent interference from power circuits.

\subsection{Product and Container Selection}

The tests were carried out according to the best practices of heat distribution studies[13]. Retorts were fully loaded with the lowest profile cans, which had the smallest diameter. Water or other convection-heating product was used as the heat distribution tests were intended to cover a wide range of products.

The retort was about 6-m long and about 1.2-m in diameter. It held six baskets of product. Each basket held six layers of cans. Divider sheets between the layers of cans were not used. The basket was about $1 \mathrm{~m} \times 1 \mathrm{~m}$ $\mathrm{x} 1 \mathrm{~m}$ in size and was made of stainless steel wire.

The holes between the wires were about $5 \mathrm{~cm} \times 5 \mathrm{~cm}$. The retort had no mercury in glass thermometer. The retort is cascading water (spray) type, in which the heating medium was hot water. The water distribution system was located at the top of the retort to allow heating and cooling water to cascade (rain down) over the containers. Air was a source of overpressure. The water was heated externally by a heat exchanger and was pumped through the system.

\subsection{Thermocouple Sensor Location}

The distribution temperature sensors were distributed among the containers in order to monitor the temperatures throughout the retort load. In addition, at least one (sometimes two) sensor was located next to the temperature-indicating device to serve as a reference against which all the other sensors can be compared.

\subsection{Equipment Calibration}

The temperature recording equipment along with the temperature sensors and wires were calibrated. The equipment (with all connections in place) was calibrated before the test by grouping all the sensors together near a known accurate standard and checking for temperature agreement at the nominal retort temperature.

\subsection{Temperature Distribution Test}

\subsubsection{Plant A (Water Immersion Retort)}

Containers were hand stacked into retort baskets and the distribution thermocouples were located in the baskets. The containers were loaded into the baskets in such a manner that represented the worst-case situation reasonably expected during normal operation. After a basket was filled, it (along with the sensor wires) was 
loaded into the retort. Time-temperature data was collected at intervals of one minute or less from the time steam was turned on to approximately 20 minutes after reaching retort temperature.

The test was performed using bare thermocouples that were distributed between the A10 cans of water over the six baskets inside the retort on three different levels, i.e. to have the worst temperature distribution during come-up time and processing time. Each basket had four rows loaded of 120 cans of water; the retort was fully loaded with the six baskets. Fifteen thermocouples were distributed in the six baskets on the top, middle, bottom and in all directions of the basket to have a representative temperature distribution. One bare thermocouple was placed near the MIG as a reference. Thermocouple distribution maps were drawn for each test.

The time/temperature data for each thermocouple was recorded from the start of the cycle till the end of the cycle time using the data logger and software logging at 0.25 minute interval. The bare thermocouples were arranged in the retort baskets at three different positions as shown in Fig. 2, and the following thermocouples distribution.

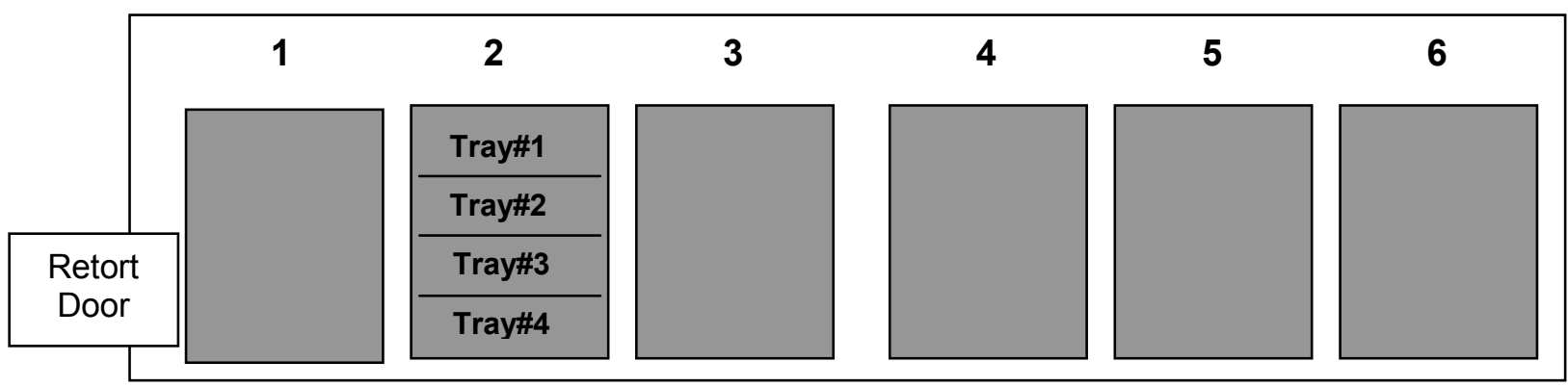

Fig. 2: Thermocouple distribution map

Table 1 shows the how the thermocouples were distributed in the baskets of the water immersion retort.

Table 1. Location of thermocouples in the water immersion retort

\begin{tabular}{l|cc}
\multicolumn{1}{c}{ THERMOCOUPLE } & BASKET & TRAY \\
\hline $\mathbf{1}$ & Bare TC & Bare TC \\
$\mathbf{2}$ & 1 & 2 \\
$\mathbf{3 , 4}$ & 1 & 3 \\
$\mathbf{5 , 6}$ & 3 & 3 \\
$\mathbf{7 , 8}$ & 4 & 2 \\
$\mathbf{9}$ & 5 & 2 \\
$\mathbf{1 0}$ & 5 & 3 \\
$\mathbf{1 1}$ & 5 & 4 \\
$\mathbf{1 2}$ & 6 & 1 \\
$\mathbf{1 3}$ & 6 & 2 \\
$\mathbf{1 4}, \mathbf{1 5}$ & 6 & 3 \\
$\mathbf{1 6}$ & 6 & 4
\end{tabular}

The scheduled sterilization program was performed in four steps: heating, sterilization, condensation, and cooling as depicted in Table 2 .

Table 2. Scheduled program during the distribution test \# 1

\begin{tabular}{l|ccc}
\multicolumn{1}{l}{ STAGE } & TIME (MIN) & TEMP $\left({ }^{\mathbf{O}} \mathbf{C}\right)$ & PRESSURE (MBAR) \\
\hline INITIAL & - & 60 & 0 \\
HEATING & 10 & 100 & 1000 \\
HEATING & 10 & 121.1 & 1800 \\
STERILIZATION & 26 & 121.1 & 1800 \\
CONDENSATION & 10 & 100 & 1000 \\
COOLING & 10 & 60 & 300 \\
COOLING & 5 & 35 & 200
\end{tabular}

\subsubsection{Plant B (Water Spray Retort)}

The bare wires of the thermocouples were distributed in the baskets along the whole length of the retort and at different locations in the basket; the locations of the thermocouples were selected to be at the bottom and middle of the baskets as these were expected to exhibit the worst temperature distribution[14].

The procedure is the same as the procedure followed in Plant A. Can sizes were $603 \times 700$. The timetemperature data during heating up, processing and cooling were recorded by the data logger and saved by the software.

Table 3 shows the how the thermocouples were distributed in the baskets of the water spray retort. 
Table 3. Location of thermocouples in the water spray retort

\begin{tabular}{l|cc} 
THERMOCOUPLE & BASKET & ROW \\
\hline $\mathbf{1}$ & Bare TC & Bare TC \\
$\mathbf{2 , 3}$ & 1 & 2 \\
$\mathbf{4 , 5 , 6}$ & 1 & 4 \\
$\mathbf{7 , 8}$ & 3 & 1 \\
$\mathbf{9 , 1 0 , 1 1}$ & 3 & 3 \\
$\mathbf{1 2}, \mathbf{1 3}$ & 5 & 2 \\
$\mathbf{1 4} \mathbf{1 5}, \mathbf{1 6}$ & 6 & 4
\end{tabular}

The scheduled sterilization program was performed in four steps: heating up, processing, cooling cycle, and cooling as depicted in Table 4.

Table 4. Scheduled program for the water spray retort

\begin{tabular}{l|ccc} 
STAGE & TIME (MIN) & TEMP $\left({ }^{\mathbf{O}} \mathbf{C}\right)$ & PRESSURE (MBAR) \\
\hline INITIAL & - & 50 & 0 \\
HEATING UP & 5 & 100 & 1000 \\
HEATING UP & 5 & 115 & 1500 \\
HEATING UP & 5 & 122 & 2500 \\
PROCESSING & 55 & 122 & 2500 \\
COOLING & 2 & 100 & 2500 \\
CYCLE & & & 2500 \\
COOLING & 25 & 50 & 1000 \\
COOLING & 2 & 50 &
\end{tabular}

III. RESULTS AND DISCUSSION

\subsection{Plant A}

The results of test $\# 1$ is illustrated in Fig. 3, which indicates the time/temperature data for all thermocouples during the period from just before the come up time till the end of the processing time and temperature range near the required sterilization temperature.

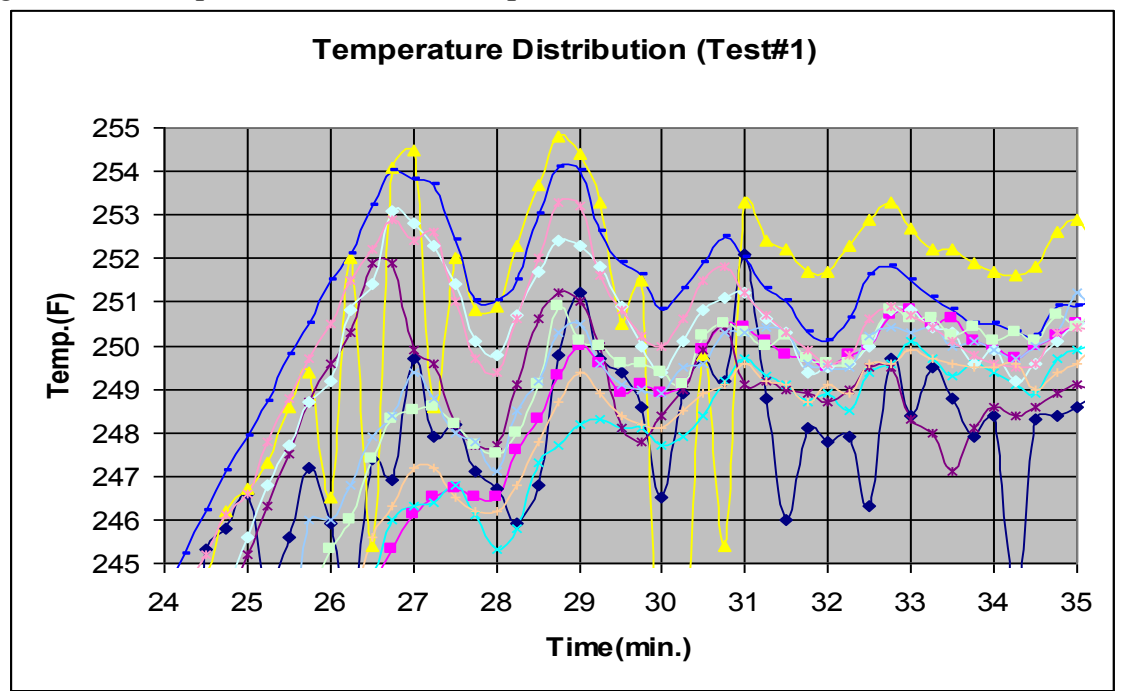

Fig. 3: Time-temperature relation in test $\# 1$

A guideline which has been used for many years indicates that the retort would have good temperature distribution if the temperature difference for the slowest thermocouple is less than $-3.0^{\circ} \mathrm{F}$ from the temperature indicating device one minute after come-up time and less than $-1.0^{\circ} \mathrm{F}$ three minutes after come-up time. It's clear from the above graph that the temperature difference at $\mathrm{t}=27.5 \mathrm{~min}$. is $3.6^{\circ} \mathrm{F}$, which is greater than $3^{\circ} \mathrm{F}$ and at $\mathrm{t}=29.5 \mathrm{~min}$. is $2^{\circ} \mathrm{F}$ which is greater than $1^{\circ} \mathrm{F}$.

Consequently, we can say that the retort has poor temperature distribution. Suggested heating-up schedule had been programmed to be used by the operator for the next test, which is based on increase of the heating up time by 3 minutes. Table 5 shows the scheduled program for test\#2. 
Table 5. Scheduled program during the distribution test \# 2

\begin{tabular}{l|ccc}
\multicolumn{1}{l}{ STAGE } & TIME $($ MIN) & TEMP $\left({ }^{\mathbf{O}} \mathbf{C}\right)$ & PRESSURE (MBAR) \\
\hline INITIAL & - & 60 & 0 \\
HEATING & 10 & 100 & 1000 \\
HEATING & 13 & 121.1 & 1800 \\
STERILIZATION & 26 & 121.1 & 1800 \\
CONDENSATION & 10 & 100 & 1000 \\
COOLING & 10 & 60 & 300 \\
COOLING & 5 & 35 & 200
\end{tabular}

The time/temperature results of test \# 2 is plotted in Fig. 4.

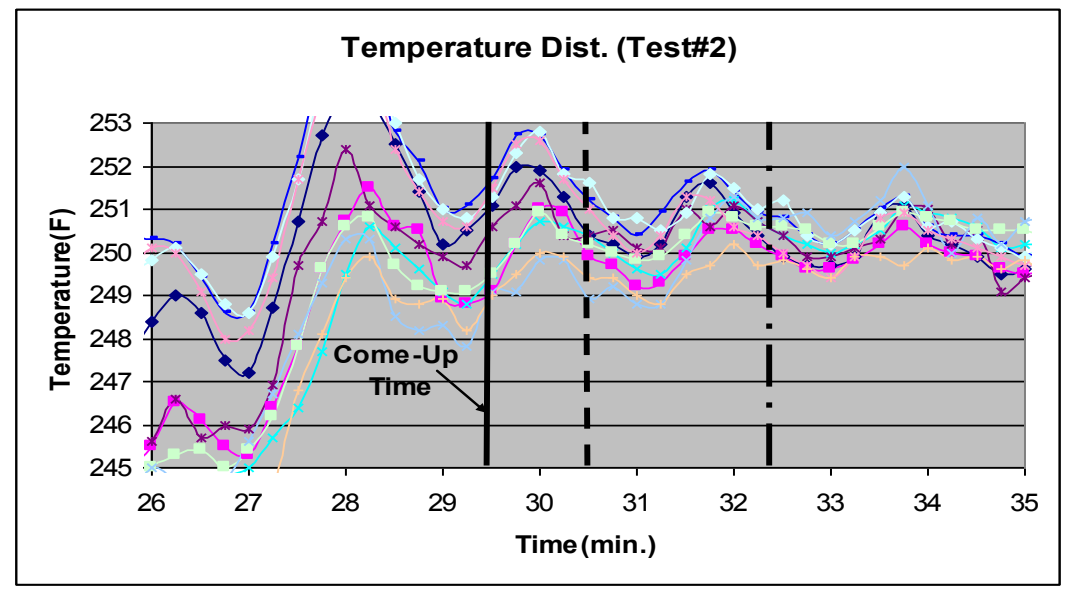

Fig. 4: Time-temperature relation in test \#2

It's clear from the above graph that the temperature difference at $\mathrm{t}=30.5 \mathrm{~min}$. is $1.2^{\circ} \mathrm{F}$, which is less than $3^{\circ} \mathrm{F}$ and at $\mathrm{t}=32.5 \mathrm{~min}$. is $0.2^{\circ} \mathrm{F}$ which is less than $1^{\circ} \mathrm{F}$. Consequently, we can say that the retort has a good temperature distribution.

Another program was implemented in which the increase of the heating up time was held at $122^{\circ} \mathrm{C}$ for the additional three minutes as indicated in Table 6.

Table 6. Scheduled program during the distribution test \# 3

\begin{tabular}{l|ccc}
\multicolumn{1}{l}{ STAGE } & TIME (MIN) & TEMP $\left({ }^{\mathbf{O}} \mathbf{C}\right)$ & PRESSURE (MBAR) \\
\hline INITIAL & - & 60 & 0 \\
HEATING & 10 & 100 & 1000 \\
HEATING & 13 & 121.1 & 1800 \\
HEATING & 3 & 122 & 1800 \\
STERILIZATION & 26 & 121.1 & 1800 \\
CONDENSATION & 10 & 100 & 1000 \\
COOLING & 10 & 60 & 300 \\
COOLING & 5 & 35 & 200
\end{tabular}

The time/temperature results of test \# 3 is plotted in Fig. 5.

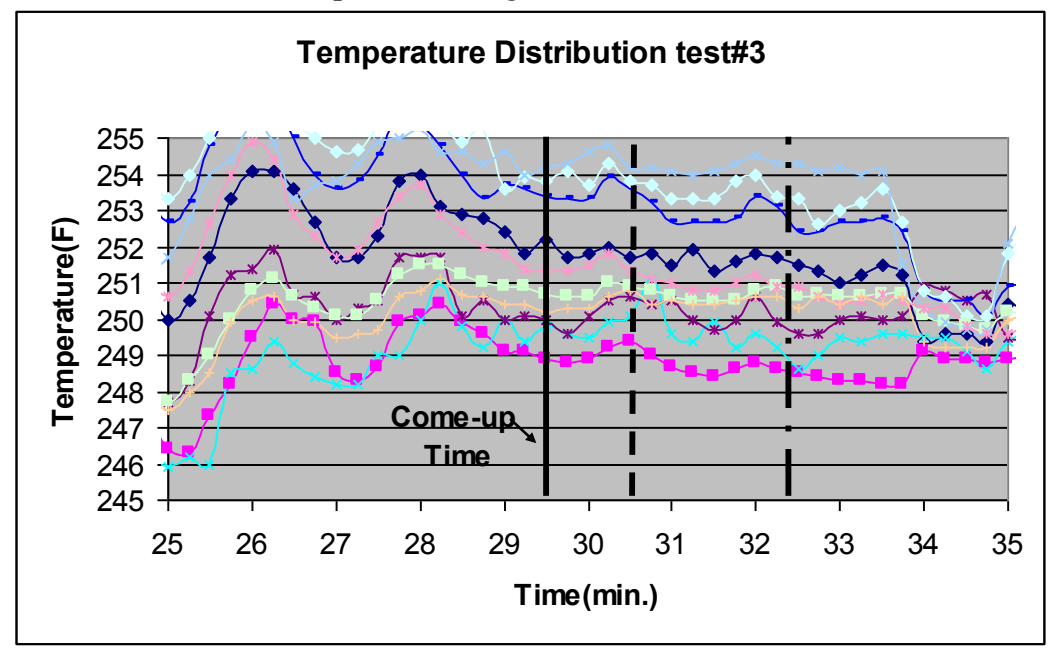

Fig. 5: Time-temperature relation in test \#3 
It's clear from the above graph that the temperature difference at $\mathrm{t}=30.5 \mathrm{~min}$. is $0.8^{\circ} \mathrm{F}$, which is less than $3^{\circ} \mathrm{F}$ and at $\mathrm{t}=32.5 \mathrm{~min}$. is $1^{\circ} \mathrm{F}$. Consequently, we can say that the retort has good temperature distribution.

As shown from the above results, the temperature distribution tests were conducted using the smallest can size available at the plant filled with water, which represented the worst conditions expected. The retort showed unacceptable temperature distribution with the operating program that was used by the company. Hence, the company's processing schedule should not be used for the processing of any product until it had been modified to the suggested programs.

This study provided two alternatives for the processing under which the retort showed an acceptable Temperature Distribution. The retort operator have the choice to process the product using the heating schedule of test\#2 or that used in test\#3. With these modification, the operating program can be used for the processing of any product on condition that the can size is the same as that used during tests or larger. Otherwise temperature distribution tests have to be performed on the new can size.

It's clear that both have good temperature distribution, it would be recommended to use the program adopted for test\#3 which gives better distribution than that adopted for test\#2. Whatever the program selected for processing was, they all have the same heating up schedule and all would have the same good temperature distribution, they will differ only in the processing time which should be calculated through heat penetration studies.

\subsection{Plant B}

Fig. 6 shows a snapshot of the software with the recorded data for the thermal distribution in the water spray retort of Plant B.

The results for this test indicated poor temperature distribution. As the retort program proceeded and ended, there were several points in the retort that did not reach the required sterilization temperature and this was an indication for a severe problem.

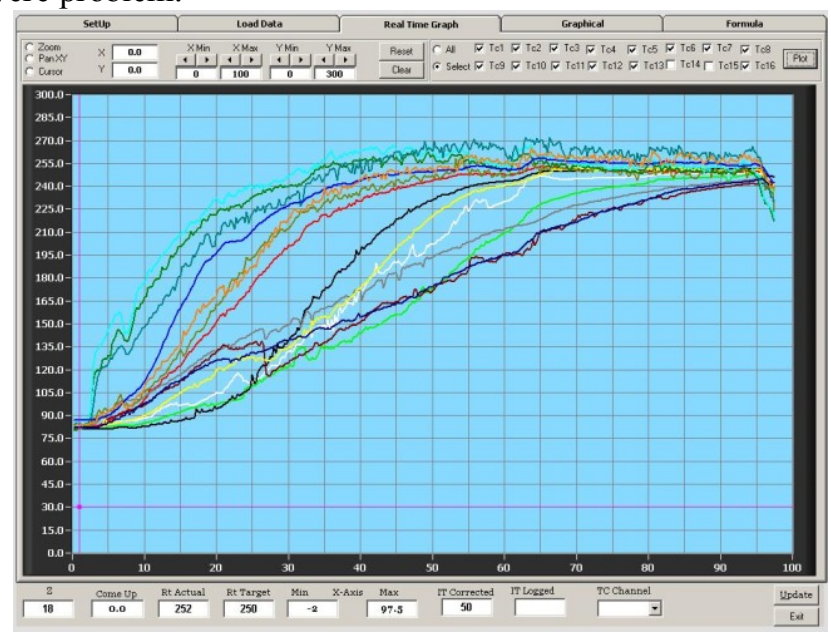

Fig. 6: Time-temperature relation in test \#4

Poor distribution could be due to mechanical problems such as fouling of retort, inlet pipes, shower plates and external heat exchanger. Mechanical checks indicated that there was fouling in the inlet pipes and that the external heat exchanger is fouled and partially clogged. After chemical cleaning of the water cycle and dismantling and mechanical cleaning of the external plate heat exchanger, the test was repeated and showed good temperature distribution as shown in Fig. 7.

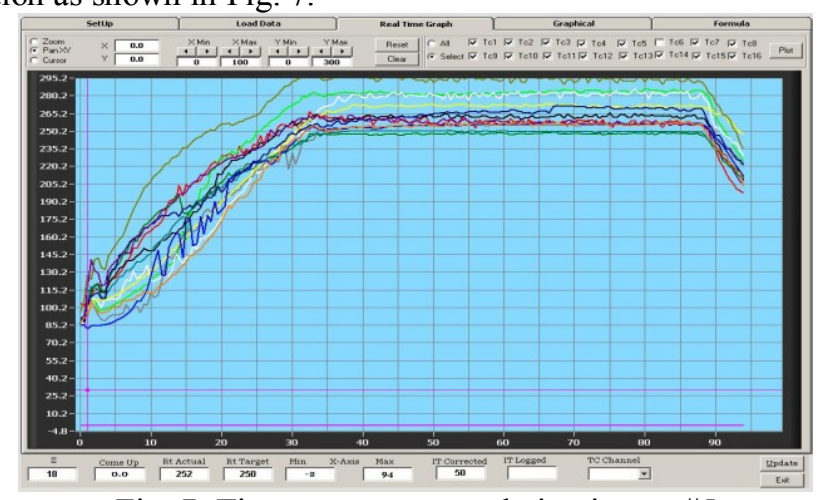

Fig. 7: Time-temperature relation in test \#5 


\section{CONCLUSION}

In this study, the sterilization process for two different types of retorts (water immersion and water spray) was investigated through five temperature distribution tests. The study led to the modification of the sterilization procedure for one of the retorts and the identification and later solution of mechanical problems in the other. Thus, temperature distribution testing is a vital tool for assuring the safety of canned food. As it is required to test the new installed retort to guide in designing the sterilization program, it is as important to conduct such testing on a regular basis at least once each 6 months. This is to ensure that the retort temperature, as indicated by the temperature-indicating device, is uniform in the entire retort environment. Temperature distribution tests will also help in identifying some severe mechanical problems affecting the consistency of the thermal processing such as fouling and partial clogging of the inlets, spray pipes and heat exchangers.

\section{REFERENCES}

[1] Bock J, Retorts for canning. (Chicago Technical Center, Metal Division, Research and Development, Continental Can Company; 1969).

[2] Weddig LM, Balestrini CG, Shafer BD, Canned Foods: Principles of Thermal Process Control, Acidification and Container Closure Evaluation. (GMA Science and Education Foundation; 2007).

[3] Kimball R, Heyliger T, Verifying the operation of steam retorts. Food technology, 44(12), 1990, 100-103.

[4] Clark JP, Thermal and nonthermal processing. Food technology, 56(12), 2002, 63.

[5] Food, Administration D, Thermally Processed Low-Acid Foods Packaged in Hermatically Sealed Containers. 1979.

[6] Siriwattanayotin S, Yoovidhya T, Meepadung T, Ruenglertpanyakul W, Simulation of sterilization of canned liquid food using sucrose degradation as an indicator. Journal of Food Engineering, 73(4), 2006, 307-312.

[7] Goncalves E, Minim L, Coimbra J, Minim V, Modeling sterilization process of canned foods using artificial neural networks. Chemical Engineering and Processing: Process Intensification, 44(12), 2005, 1269-1276.

[8] Farid M, Abdul Ghani A, A new computational technique for the estimation of sterilization time in canned food. Chemical Engineering and Processing: Process Intensification, 43(4), 2004, 523-531.

[9] Choi S-H, Cheigh C-I, Chung M-S, Optimization of processing conditions for the sterilization of retorted short-rib patties using the response surface methodology. Meat science, 94(1), 2013, 95-104.

[10] Teixeira A, Tucker G, On-line retort control in thermal sterilization of canned foods. Food Control, 8(1), 1997, 13-20.

[11] Alonso AA, Arias-Méndez A, Balsa-Canto E, Garcia MR, Molina JI, Vilas C, Villafin M, Real time optimization for quality control of batch thermal sterilization of prepackaged foods. Food Control, 32(2), 2013, 392-403.

[12] Syafiie S, Tadeo F, Villafin M, Alonso AA, Learning control for batch thermal sterilization of canned foods. ISA transactions, 50(1), 2011, 82-90.

[13] Downing DL, A Complete course in canning and related processes. CTI Publications; 1996).

[14] Bichier J, Teixeira A, Balaban M, Heyliger T, Thermal Process Simulation of Canned Foods under Mechanical Agitation. Journal of food process engineering, 18(1), 1995, 17-40. 